\title{
How Can Households Eat in austerity? Challenges for Social Policy in the UK
}

\author{
Elizabeth Dowler* and Hannah Lambie-Mumford** \\ *Department of Sociology, University of Warwick \\ E-mail: Elizabeth.Dowler@warwick.ac.uk \\ ** Sheffield Political Economy Research Institute (SPERI), University of Sheffield \\ E-mail: h.lambie-mumford@sheffield.ac.uk
}

In the United Kingdom many households are seeing their food security suffer through rising food and fuel prices, economic recession and welfare reform. Household budgeting priorities by necessity tend to be towards expenditures whose default consequences are severe; food budgets are where people can and do make economies. People manage variously on minimal diets, food gifts and charitable support, but the consequences in terms of social wellbeing and nutritional health, while potentially severe, are hidden and individually embodied rather than monitored and addressed by society. This article discusses the potential consequences of these shifts in household food provisioning under conditions of increasing austerity. The challenges posed for social policy are explored, particularly in relation to changes in welfare provision, the increasingly prominent role of the voluntary and community sector and potential devolution of responsibilities to local levels.

Keywords: UK, food poverty, food policy, food aid, food banks.

\section{Introduction}

In the United Kingdom (UK), many households are seeing their food security suffer through rising food and fuel prices and the effects of the economic recession and social welfare reform. This article aims to contribute to social policy research with evidence and insight on the ways in which households have been managing their food experiences in the context of austerity, examining changes in household provisioning and eating habits over the past few years, and with particular evidence demonstrating that people are increasingly drawing on charitable food assistance. The implications of this evidence are discussed in the light of on-going changes to social security, labour markets and responsibilities at local and national levels. The article draws on several years of empirical and policy research by the authors, as well as recent reviews of household and local practice, to set out an exploratory agenda for social policy research and cross-sectoral policy response.

Ensuring all people in the UK have the means to eat decently and sufficiently to maintain good health is an increasing policy challenge. The combination of higher (and rising) food and fuel prices, with static (or falling) incomes means more and more households are facing food poverty, or what is more often understood as food insecurity. This latter concept, largely unfamiliar to the general public and many in the social policy world, is widely used internationally, including in North America, and has also recently been adopted by the UK Department of Environment, Food and Rural Affairs (Defra). It 
refers to 'the inability to acquire or consume an adequate quality or sufficient quantity of food in socially acceptable ways, or the uncertainty that one will be able to do so' (Dowler, 2003: 151, citing Riches, 1997). Such understanding thus links the individual experiences of hunger to 'the debate about welfare policy and social security reforms, but moves beyond it and engages questions of basic human rights' (Riches, 1997: 11), while recognising food as a social good, the ultimate intimate commodity. Food security then encompasses the need for sustainable and sufficiently secure livelihoods or other sources of income which provide enough money to afford the food needed to meet health and social necessities, money which can be protected against other expenditure demands. It implies physical and economic access to shops or markets (which can be online as well as by car, bus or walking) where appropriate, healthy food is sold at affordable prices. Critically, it also refers to a sense of security: that people feel confident of being able to provide for themselves and their family, now and in the future (Dowler et al., 2011).

\section{Incomes and food in austerity}

The economic recession over the last five years has affected the UK economy as elsewhere in Europe, and has contributed to rising insecurity in jobs and income as people have faced loss of hours, stagnant or falling wages and growth in flexible work contracts, as well as actual unemployment (Irving, 2013). The Coalition Government, formed after the 2010 general election, aimed to reduce the economic deficit as fast as possible, partly through reductions in public spending, and as part of this strategy introduced increasingly harsh social security reforms aimed at strategic and systematic reductions in welfare provision. These are discussed in detail elsewhere. ${ }^{1}$ There have been three important outcomes, Firstly, many of these reforms were implemented over time, such that their full force has only really been apparent since April 2013 when several signalled changes came into effect. ${ }^{2}$ Secondly, households and individuals can be affected by several different elements of the reforms together (Aldridge and Maclnnes, 2014). Thirdly, the financial impact varies considerably around the country: in general, the more deprived the local authority, the greater the financial loss (Beatty, and Fothergill, 2014). Thus some households living in generally poorer areas, not only have lower incomes because of changes to tax and social security benefits (both in- and out-of-work), but may also face reductions in local-level support such as children's clubs, day centres and child care, many of which offered subsidised food as well as enabling people, particularly mothers of young children, to take paid work. In addition, housing costs, which are high in the UK, also vary widely geographically, which has consequences not only for households with insufficient incomes to cover basic needs, but also, due to the likelihood of facing a benefit cap set at median net earnings for a working household, for those paying high rent. Many of these changes have had a marked gendered effect: women are more likely to bear the brunt of employment and social security cuts, while also primarily shouldering caring responsibilities. Lone parents, the majority of whom are women, are particularly likely to be badly affected (Women's Budget Group, 2012; Cracknell, 2013).

At more or less the same time as the recession, food prices increased rapidly in 2007-8 and have continued to increase at above the rate of inflation. ${ }^{3}$ These increases, which vary in size between commodities, are the result of problematics in the global food system (Lang et al., 2009) as well as the economic crises: in particular, rising costs of inputs (especially oil), EU support for biofuels, growing global demand for grain-fed 
meat and financial speculation, have been cited as major factors contributing to rising food prices (De Schutter, 2010). Despite some fluctuation and considerable effort from the major retailers to cut costs and compete on price, food prices are unlikely to come down in the near future; indeed, many argue that 'cheap food' is an inappropriate goal for governments and supermarkets alike (for example, Food Ethics Council, 2010). The consequences are, as noted by Defra (2013: 26), 'falling income (after housing costs) and rising food prices produced a double effect, reducing food affordability by over $20 \%$ for lowest income decile households'. On average, UK households spend 11.2 per cent of total expenditure on food, but the lowest income decile households spend 16.6 per cent, which is about twice as much as the highest decile (Defra, 2013), ${ }^{4}$ although, of course, they spend considerably less money in total on food than richer households.

In the 2011 Family Food survey, Defra particularly examined the effects of rising prices on low-income households' food purchases (Defra, 2012). Although many households had traded down to cheaper commodities since the marked rise in food prices, those in the lowest decile had not, probably because they were already buying the cheapest food available. Nearly two-thirds in the survey said that the price of food was an issue of considerable concern, which echoes the findings of research funded by Defra in 2010 using an online survey and consumer workshops (Dowler et al., 2011). In practice, those in the lowest income deciles spent 17 per cent less on food in 2011 than in 2007, buying significantly fewer portions of fruit and vegetables than previously (their purchase levels had already been lower than those of higher income groups) and less fresh meat, fish and soft drinks (Defra, 2012). These households also purchased more processed meat products, which implies a lower nutritional quality of diet. These findings are strengthened by recent analyses from the Institute of Fiscal Studies, using data from the Living Costs and Food Surveys 2005-11 and Kantar Worldpanel data (Griffith et al., 2013), which also show that all household types reduced purchases of fruit and vegetables and increased the share of calories purchased as processed foods. While the nutritional quality of foods purchased declined in all households between 2005-7 (i.e. pre-recession and price increases) and 2010-12, it fell most in households containing pensioners, lone-parents and households with young children. ${ }^{5}$ Thus, while those in such households have long been more likely to have diets which are inadequate for health (Dowler et al., 2007), these analyses imply that the differences between low-income and richer households have become more marked under conditions of economic austerity.

It is, of course, possible to obtain a nutritionally adequate diet by consuming a range of different dietary patterns; nevertheless, these national data sets show that those in lower income households are increasingly consuming diets which, while they might broadly satisfy caloric needs (people are not regularly hungry), are poor in micro-nutrient density and dietary variety. Both of these are likely to lead to poorer health outcomes in the short and longer term (Dowler et al., 2007). Food, of course, also has significant social and cultural value, ensuring identity, opportunity for hospitality and pleasure (Wills, 2011). People are thus increasingly embodying the effects of economic austerity and increasing costs of food, both in their present and future health experiences, and in social exclusion.

\section{Household management strategies for food}

The evidence cited so far is largely of outcomes and their effects, in terms of what people have been able to spend on food, what they have bought and the nutritional content. The 
other side of the coin is to examine how households manage money and other resources to obtain food, particularly under austerity: what is it that people do, and why? Until recently, there was little work specifically looking at food management strategies under recent conditions of austerity in the UK, although those who have used qualitative, indepth methods to examine more general impacts on households and the ways in which those in poorer households have tried to cope (or not), often comment that people have reported having to reduce food expenditure in order to meet more pressing needs, and that this is a considerable source of stress.

Managing food is a regular element of domestic practice which is often performed unconsciously, aiming to reproduce intimate but purposeful acts of social identity while also meeting individual needs and preferences (for example, Lupton, 1996). It is therefore often difficult for people to articulate their ways of eating with a reduced budget other than by simple reference to cutting back on expenditure, 'eating less', or 'throwing less away'; and distressing for them if they are asked to account for thinking and behaviour which provides evidence of negative consequences of their attempts to cope. Such experiences are hard to capture in standardised, quantitative surveys or semi-qualitative telephone exchanges, and require more in-depth, sensitive investigation (for example, Dowler, 1997; Hossain et al., 2011; Goode, 2012). What such research reveals is that budgeting priorities, by necessity, tend to be towards those expenditures whose default consequences are severe, such as rent, fuel bills, local taxes, servicing debts. The food budget is where people can and do make economies, although people also report reducing their fuel and other bills, or relying on credit, to buy food when very pressed.

The food strategies which people articulate include buying much cheaper food (which they usually regard as of poorer quality or unacceptable to cultural patterns) or so-called 'fast food' ${ }^{6}$ because it requires no cooking. Many report spending more time and effort to obtain and prepare food, for instance, traveling to cheaper supermarkets rather than local familiar shops, planning menus and shopping with great care and making use of price promotions and offers where these offer benefit. However, some in fact cease bulk buying or using any strategy other than simply buying what is needed for that day or even meal, because of having insufficient money to do other than live 'hand-to-mouth'; previous economies of scale (in money and time) are abandoned. People also often say they have become very resourceful in using 'leftover' food, throwing much less away, and of borrowing money and/or food from relatives, neighbours or other friends. Some accounts are painful to articulate as well as endure: 'We have spoken to people living on one meal a day, drinking hot water and lemon to tame hunger pangs, trying to think how they can survive on a household budget of $£ 6$ a week. More than half a million children in the UK are now living in families who are unable to provide a minimally acceptable

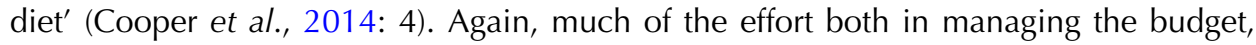
and in reducing own intake or going without food, is done by women in the household (Attree, 2005).

Those on means-tested benefits with school-age children rely on them obtaining a free midday meal at school during term-time, and sometimes breakfast or food at afterschool clubs as well. Anecdotally many parents find the long school vacations extremely difficult when these benefits are unavailable. Finally, those with children often mention that they themselves regularly go without food to ensure their children get enough to eat. 


\section{'Managing' with charitable help}

These strategies and more have been shown through qualitative research and people's own accounts, but in recent years there has been increasing evidence of people in extreme need having to ask for external help from 'food banks' and other charitable providers to enable them to eat. Although there is a long history of such help in the UK, what is remarkable in recent years is the numbers asking for help and emerging evidence of factors driving such demand. These factors are much debated and discussed in the media, online and in government; the controversies generated are unlikely to be resolved by a current, ongoing All Party Parliamentary Inquiry (APPG, 2014).

Practices vary: the largest emergency food provider, the Trussell Trust Foodbank Network, offers three days' worth of food (enough for ten meals) for a given household size, to those given referral vouchers by a local professional (such as a social worker, health visitor or housing officer), to a maximum of three vouchers per crisis. The nonperishable, in-date food needed to make up the parcels is sourced from local people through churches, schools and businesses, although increasingly, supermarket special events or specific donations are required. Trained volunteers collect, sort and distribute the food, and signpost further help. Other charitable projects are more varied in the amount of food given and its nature, criteria for access, how often and when open, and in advice and signposting to other sources of help; most also rely on trained volunteers. There are other community-based activities which use food provision to draw in and help clients or members, where the primary objective is to offer something else: for example, education (school breakfast clubs), sanctuary (domestic violence refuges), support (drug rehabilitation) or company (day-care centres). All these institutions also make use of freely donated food, sometimes through the national network FareShare, a charity which enables judicious usage of 'surplus' or 'waste' food from the food and drink industry to be channelled to projects serving need.'

In addition, there are longstanding local food projects of various kinds, often supported through public health or community development (Dowler et al., 2007), which include soup runs or meal programmes, as well as many initiatives which seek to redress meagre food access (local food buying co-operatives, community run shops or social enterprises), improve food handling skills or facilitate food growing. Many such initiatives specifically focus on low-income households or poorer communities, or particularly encourage participation by those with fewer social or material resources, but few can provide large-scale emergency food relief to households or individuals in crisis, unless set up specifically for this purpose. These various initiatives operate with a range of criteria, systems and practice, and, despite efforts, no consistent, established national database exists. Thus 'food poverty' is both a longstanding experience in the UK, and has been partially addressed more by various types of local support than by national policy initiatives. The Trussell Trust Foodbank Network, while currently very important, is by no means the only source of regular food help for those in need, whether an emergency and 'temporary', or more long-term.

Nevertheless, what is clear is that there has been an unprecedented and dramatic rise in those asking for such help over the last couple of years, even though numbers are hard to establish reliably (Dowler and Lambie-Mumford, 2014). For instance, Trussell Trust data show that, during 2013-14, it distributed more than 900,000 emergency food parcels to households in need, a huge increase on the 61,500 supplied in 2010-11 
(Trussell Trust, 2014). There has also been a large increase in the numbers of food banks set up, from fifty-four in 2009 to 425 by mid-2014 (Lambie-Mumford, 2013; Trussell Trust, 2014), and, anecdotally, other food provision systems have similarly proliferated over the same time period. However, providers also emphasise that existing food provision has faced considerable increase in demand since early 2013 (Cooper et al., 2014), such that rising numbers seeking charitable support cannot simply be attributed to there being more food aid outlets and more publicity (as claimed by government). The recent review of emergency food aid for Defra similarly found that more people were needing help so that supply increased to meet demand (Lambie-Mumford et al., 2014); increasingly, some providers speak of being overwhelmed by the need, and a number are organising into more systematic networks in order to source food and manage processes more efficiently. These shifts in policy and practice, some of which are driven by grassroot responses or civil society, are at present largely undocumented or monitored. What is clear is that growing numbers of households are unable to manage food budgeting shortfalls through the many semi-formal support mechanisms described above.

The reasons behind such rapid and growing demand are much discussed and debated in the social media and the press, and to some extent in government (for example, Hansard, 2013). The evidence from the review for Defra and surveys by providers is that the majority who seek such help do so from desperation, it is not a casual alternative to other coping strategies but an action of 'last resort' (Lambie-Mumford et al., 2014; Perry et al., 2014). People are asking for immediate and specific help with food to get through difficult, and what they hope are temporary, circumstances, such as the gap between the loss of a job and initiation of social security benefits, or when social security errors or delays occur, or 'sanctions' are imposed ('sanctions' refers to situations where the payment of benefit is withheld because claimants do not meet conditions set. The majority come through JobSeekers Plus Centres, and can be for four to twenty-six weeks or longer). ${ }^{8}$ Such financial crises are particularly hard for households where budgets have been overstretched for some time; increasing numbers have no savings or too small a reserve to cushion against sudden shocks (Which, 2013a, b). The Citizens Advice Bureau (one of the sources of referral vouchers for foodbanks) has surveyed its members to establish why so many now need food help:

We are continuing to see a steady rise in the numbers of clients requiring emergency food provision ... bringing the total to over 27,500 for the last twelve months. The preliminary findings of research we have conducted into the cause of food need ... indicates that the main immediate causes are, firstly, delays in benefit payments which leaves clients with significant gaps in income. And, secondly, clients whose benefits have been sanctioned and therefore who have been left without any income. (Citizens Advice Bureau, 2014: 24)

It is also the case that people increasingly come to food banks because their regular income from low wages is too low to withstand sudden extra demands, or their levels of indebtedness have become unmanageable.

Thus the Citizens Advice Bureau and other front-line services, food bank managers and social service officers, as well as some press and politicians, argue that rising use of emergency food aid through food banks is evidence that increasing numbers of economically vulnerable households can no longer cope with the effects of economic recession and public spending cuts on wages and local support, and particularly with the 
extensive, rapid changes to social security processes and entitlements. In the absence of any systematic survey of food bank clients or those using other sources of free food, the evidence on why so many more people claim to be in need is inevitably partial since it has relied on different recording systems and indicators (although a number of food providers are currently tightening their recording systems), and sometimes is anecdotal. Nevertheless, the accounts given are remarkably consistent, and certainly bear close scrutiny. There have been several public calls for a government response. For example, just before Easter 2014 a group of leading Christian clergy and other faith leaders wrote to the main party leaders to challenge the moral position of a rich country with rising numbers unable to feed themselves adequately, and to call for a concerted response; this built on an earlier letter by a group of Anglican Bishops (Beattie, 2014; Butler, 2014). Similarly, the Faculty of Public Health issued a letter from nearly 200 professionals, calling for a government response (Ashton et al., 2014).

\section{Social policy consequences: clearer understanding and moral choices}

There are a number of issues to consider both in terms of current and potential policy responses and consequences of the rapid changes which these events and initiatives have engendered, which can only be outlined in the space available here. Better understanding of the complexities of food poverty experiences and causes, both underlying and immediate, and a willingness to address the fundamental and cross-sectoral nature of responses, are essential.

We should note that a number of local authorities have begun inquiries and initiatives; these can address some local issues, but not those which relate to fiscal or social policy and matters of national planning (see, for example, Greater London Authority, 2013; Maslen et al., 2013, among several). In addition, more than a third of local councils in a recent survey for BBC Panorama said they were providing funds to support local food banks, drawing on $£ 2.9$ million of public money to help feed people (BBC, 2014) (this money may have come from the recently devolved emergency funds for households in need, see note 2). It is questionable how sustainable and appropriate is the trend for local councils to be diverting these monies to local food banks (Butler, 2013). Such action may have temporarily helped local-level emergency food provision by providing financial help, but it is also likely to have deprived some households who were in desperate need of it of the actual cash to which they might previously have been entitled. While all need to eat every day, some also urgently need to pay demanding debtors or meet other expenditures; the general lack of sufficient money for household survival (in the social as well as physiological sense) is what has driven emergency provision demand, and the loss of emergency loans has exacerbated the very difficult circumstances which some households face (Royston and Rodrigues, 2013).

Critically, there is a danger of tacit assumptions about the appropriateness of charitable food systems becoming embedded into, and to some extent replacing, social systems of support which hitherto were supplied by the state. Notwithstanding some church and other networks establishing signposting to state and other support, as well as practical help with skills and material goods (such as furniture, clothing) along with the food, such systems lack accountability and transparency, and how far they are subject to regulation is unclear. Volunteers in franchised operations, for instance in The Trussell Trust Foodbank Network, or Citizens Advice Bureaux, undergo training and are accountable 
at local levels; those volunteering in other food banks or initiatives may or may not be trained, and may or may not have Child Protection cover, local-level indemnity or other systems of monitoring and accountability. Some faith groups have particular views on social practices, and it is not clear whether rules which reflect these views are applied, transparently or otherwise, in food provision initiatives.

More fundamentally, there is no recent precedent in the UK for the inadequacies of waged work or social security being met through (largely unaccountable) citizen action in feeding those who are unable to afford to feed themselves and their dependents. It is not part of the current social contract that social protection be replaced or supplemented by unaccountable, unsystematic volunteer help, and growing numbers involved in such provision are uncomfortable with the role they are being asked to play. Emergency food provision cannot replace an accountable system of social protection, as experience in the USA and Canada demonstrates (Poppendieck, 2014; Riches and Tarasuk, 2014).

Although some emergency provision systems, notably the Trussell Trust Foodbank Network, rely on voluntary contributions of food from local citizens, increasingly the main UK models of food provision draw on redistributing that within the food system which is labelled 'food waste'. Although this might more appropriately be referred to as 'surplus', since it does not refer to plate waste but that which is a by-product of the complexities of the modern food system destined for landfill or anaerobic digestion, the terminology of 'food waste' is negative and its usage deeply demeaning as a solution to those in need. The covert, tacit institutionalisation of charitable responses also runs the risk of contributing to these important issues and distinct dysfunctions in our food and socio-economic systems being sidelined and depoliticised, particularly through the rhetoric of solutions located in 'proper use of resources' at local levels. This enables both the state to retreat from responsibilities and food businesses to gain from improving corporate social responsibility and reduced landfill taxes. There is no real gain to those who are bearing the brunt of economic austerity in the UK today.

Finally, of course, there is a long history of 'food poverty' being seen as the result of personal or household inadequacies in domestic management of budgeting, sourcing and cooking food. The challenge to human efficiency arguments on the grounds of inadequacies of income (from waged work or social security) is well rehearsed and as consistently ignored, since it suits governments to reduce public expenditure and pass on responsibility for the health and social consequences for inadequate food intakes to those who experience and embody them (Dowler, 2003).

\section{Social policy consequences: future research and intervention}

The serious and complex issues set out in this article represent a moral, economic and social challenge to the UK state and its citizens. Some of the urgent research needs are obvious from the account of the problem:

- to set up systematic monitoring of those at risk of food poverty at local and national levels, with clear links to policy responsibilities and responses

Indicators could be explored, such as numbers who have claimed social security benefits or worked at the National Minimum Wage for, say, more than a year. Such data could be presented by different household types, for example, matching those used in Minimum Income Standards (Davis et al., 2014). These data could be combined with regional 
or district-level data on housing costs (and perhaps fuel) and numbers on zero hour or six-monthly contracts, to indicate where essential expenditure would particularly squeeze household budgets for those on very and/or insecure low incomes.

- to establish standards for minimum acceptable incomes below which household income should not fall through action by the state or other parties

This would explore the usage of Minimum Income Standards (Davis et al., 2014) or some similar basis for estimation, in statutory systems such as fines, National Minimum Wages, debt repayments, etc.

- to explore and clarify the reasons why asking for emergency food aid is rising Many food aid providers are currently working to improve their data collection systems both to register 'repeat users' and to be more systematic in recording details within previously broad categories of 'benefit problems'. However, such information is often quite complex, and more in-depth research is needed to understand why people have found their way to a food bank. Such studies are also being done, but usually starting, of necessity, from the experiences of being a client. Systematic, qualitative research not necessarily involving food bank clients is also needed on the strategies households adopt, and what factors in state or others' practice help or hinder their management.

- to gather views and visions from those living in poverty on how their food needs might more reasonably be met

There is a need to situate responses more clearly in the realities of peoples' lives, giving them opportunity to voice frustrations but also possibilities for improvement in their food security. Such research should clearly link to policy responsibilities at local and national levels.

Future policy responses need to ensure household food security: that people have sufficient income they can devote to food expenditure rather than other needs, and economic and physical access to places in which they can grow or buy sufficient, affordable food for health, and which meets cultural needs. In addition, people need a sense of security, that such access is sustainable in the immediate and longer-term future. Social welfare systems have also traditionally included food support in kind and regulation of practice: through schools, for young children, and, in the past, sometimes for working populations through subsidised canteen provision. Space precludes discussion of these issues, but it is important to note the increasing number of local-level food initiatives in the UK which draw on public sector and civil society partnerships to help in provisioning, including possibilities for growing or rearing food. Systematic and sustained financial and other support for such practices would in fact help the majority of households, many of whom are deeply under-capitalised to withstand economic shocks or continually squeezed budgets.

The premise for such social policy intervention in food as there has been in the UK has usually been either welfare support (see Lucas et al., 2015) or the development of human capital. Internationally, there is a widespread recognition of rights-based approaches to ensuring access to sufficient, safe, appropriate food (Riches and Silvasti, 2014), a framework which imposes obligation rather than recommended options on the state and carries with it civil and political rights, which must be implemented in practice, in national law. A rights framework also introduces accountability, and implies a normative basis to responses rather than that of charity or emergency. Such an approach has yet to gain 
much currency in the UK (Dowler and O'Connor, 2012), despite the efforts of civil society organisations (for example, Just Fair, 2014), and there is, as yet, no duty on government or local authorities to ensure that affordable food is available in local shops, or that people have sufficient income to obtain food. Nevertheless, the current unprecedented situation whereby possibly a million citizens are being fed through emergency charitable giving because they cannot sustain themselves through work or social protection demands some urgent critical thinking and creative imagination.

\section{Notes}

1 See, for example, the first sections of Social Policy Review 23, 24 and 25 (2012, 2013, 2014).

2 These include implementation of the 'removal of spare room subsidy' from Housing Benefit (so-called 'bedroom tax') (Department for Work and Pensions, 2013); Discretionary Crisis Loans and Community Care Grants were abolished in April 2013, and localised schemes involving less, non-ringfenced monies, came into effect simultaneously (Kennedy, 2012).

3 In 2013, Defra reported that all foods had risen in price since 2007, with increases ranging from 19 per cent to 47 per cent depending on commodity (for example, fruit and vegetable prices rose by around 25 per cent) (Defra, 2013).

4 These data, from Defra, are from the Household Income and Expenditure Survey, which differ from the Living Costs and Food Survey used by Griffith et al. (2013).

5 The report does not state whether adjustment was made for households throwing away less food as prices increased, which emerges from Defra evidence.

6 'Fast food' varies considerably in type, cost and potential contribution to a healthy diet. However, the general assumption in policy and public health circles is that most is unlikely to help with the latter.

7 FareShare, [online at] http://www.fareshare.org.uk/.

8 https://www.gov.uk/government/news/benefit-sanctions-ending-the-something-for-nothingculture and http://www.adviceguide.org.uk/wales/benefits_w/benefits_benefits_in_work_or_looking_for_ work_ew/benefits_for_people_looking_for_work.htm\#h_jobseekers_allowance_and_sanctions.

\section{References}

Aldridge, H. and Maclnnes, T. (2014) Multiple Cuts for the Poorest Families, Oxford: Oxfam, New Policy Research Institute.

APPG (2014) The All-Party Parliamentary Inquiry into Hunger and Food Poverty, http:// foodpovertyinquiry.org/ [accessed 24.07.2014].

Ashton, J. R., Middleton, J. and Lang, T. (2014) 'Open letter to Prime Minister David Cameron on food poverty in the UK', on behalf of 170 signatories, Lancet, 383, 9929, 1631.

Attree, P. (2005) 'Low-income mothers, nutrition and health: a systematic review of qualitative evidence', Maternal and Child Nutrition, 1, 4, 227-40.

BBC (2014) 'Councils spending $£ 3 \mathrm{~m}$ on food poverty and food banks', http://www.bbc.co.uk/ news/uk-26369558 [accessed 24.07.2014].

Beattie, J. (2014) '27 bishops slam David Cameron's welfare reforms as creating a national crisis in unprecedented attack', Daily Mirror, 19 February, http://www.mirror.co.uk/news/uk-news/27-bishopsslam-david-camerons-3164033 [accessed 27.07.2014].

Beatty, C. and Fothergill, S. (2014) 'The local and regional impact of the UK's welfare reforms', Cambridge Journal of Regions, Economy and Society, 7, 1, 63-79.

Butler, P. (2013) 'Food vouchers to provide emergency help but prevent spending on alcohol', The Guardian, 26 March, http://www.theguardian.com/politics/2013/mar/26/payment-cardsemergency-assistance-food-stamps [accessed 24.07.2014]. 
Butler, P. (2014) 'Hunger is a "national crisis", religious leaders tell Cameron', The Guardian, 16 April, http://www.theguardian.com/society/2014/apr/16/million-people-britain-food-banks-religiousleaders-faith-groups [accessed 27.07.2014].

Citizens Advice Bureau (2014) Advice Trends: Quarterly Client Statistics of the Citizens Advice Service in England and Wales 2013-4, Quarter 4, http://www.citizensadvice.org.uk// advice_trends_may_2014.pdf [accessed 24.07.2014].

Cooper, N., Purcell, S. and Jackson, R. (2014) Below the Breadline: The Relentless Rise of Food Poverty in Britain, Manchester: Church Action on Poverty, Oxfam, Trussell Trust, http://www.church-poverty.org. uk/breadline [accessed 24.07.2014].

Cracknell, R. (2013) 'Estimating the costs of tax and benefit changes by gender', Commons Library Standard Note 06758, House of Commons Library, London.

Department for Work and Pensions (2013) Local Authorities and Advisers: Removal of the Spare Room Subsidy, London: DWP, https://www.gov.uk/government/organisations/department-for-work-pensions/ series/local-authorities-removal-of-the-spare-room-subsidy [accessed 10.12.2014].

Davis, A., Hirsch, D. and Padley, M. (2014) A Minimum Income Standard for the UK in 2014, York: Joseph Rowntree Foundation.

De Schutter, O. (2010) 'Food commodities speculation and food price crises: regulation to reduce the risks of price volatility', United Nationals Special Repporteur on the Right to Food Briefing Note 02, http://www.srfood.org/images/stories/pdf/otherdocuments/20102309_briefing_note_02_en_ok.pdf [acccessed 24.07.2014].

Defra (2012) Family Food 2011, London: Department for Environment, Food and Rural Affairs.

Defra (2013) Food Statistics Pocketbook 2012 (in year update), London: Department for Environment, Food and Rural Affairs.

Dowler, E. (1997) 'Budgeting for food on a low income: the case of lone parents', Food Policy, 22, 5, 405-17.

Dowler, E. (2003) 'Food and poverty in Britain: rights and responsibilities', in E. Dowler and C. Jones Finer (eds.), The Welfare of Food: Rights and Responsibilities in a Changing World, Oxford: Blackwell Publishing, pp. 140-59.

Dowler, E., Caraher, M. and Lincoln, P. (2007) 'Inequalities in food and nutrition: challenging "lifestyles"', in E. Dowler and N. Spencer (eds.), Challenging Health Inequalities: From Acheson to 'Choosing Health', Bristol: The Policy Press, pp. 127-55.

Dowler, E., Kneafsey, M., Lambie, H., Inman, A. and Collier, R. (2011) 'Thinking about "food security": engaging with UK consumers', Critical Public Health, 21, 4, 403-16.

Dowler, E. and O'Connor, D. (2012) 'Rights-based approaches to addressing food poverty and food insecurity in Ireland and UK', Social Science and Medicine, 74, 1, 44-51.

Dowler, E. and Lambie-Mumford, H. (2014) Food Aid: Living with Food Insecurity, Working Papers of the Communities and Culture Network, Leeds: Communities \& Culture Network.

Food Ethics Council (2010) Food Justice: The Report of the Food and Fairness Inquiry, Brighton: Food Ethics Council, http://www.foodethicscouncil.org/uploads/publications/2010\%20FoodJustice.pdf [accessed 24.07.2014].

Greater London Authority (2013) A Zero Hunger City - Tackling Food Poverty in London, London: Greater London Authority.

Goode, J. (2012) 'Feeding the family when the wolf's at the door: the impact of over-indebtedness on contemporary foodways in low-income families in the UK', Food and Foodways: Explorations in the History and Culture of Human Nourishment, 20, 1, 8-30.

Griffith, R., O'Connell, M. and Smith, K. (2013) Food Expenditure and Nutritional Quality over the Great Recession, IFS Briefing Note BN 143, London: Institute of Fiscal Studies.

Hansard (2013) Debate on Food Banks, volume 572, column 806, 18 December, House of Commons, http://www.publications.parliament.uk/pa/cm201314/cmhansrd/cm131218/debtext/131218-0003. htm\#13121855000003 [accessed 24.07.2014]. 
Hossain, N., Byrne, B., Campbell, A., Harrison, E., McKinley, B. and Shah, P. (2011) The Impact of the Global Economic Downturn on Communities and Poverty in the UK, York: Joseph Rowntree Foundation.

Kennedy, S. (2012) 'Localisation of the social fund', Commons Library Standard Note 06413, http://www.parliament.uk/business/publications/research/briefing-papers/SN06413/localisation-ofthe-social-fund [accessed 24.07.2014].

Irving, Z. (2013) 'Themed section: work, employment and insecurity', Social Policy Review, 25, $203-6$.

Just Fair (2014) Going Hungry? The Human Right to Food in the UK, London: Just Fair, http://just-fair.co.uk/ hub/single/going_hungry_the_human_right_to_food_in_the_uk/ [accessed 24.07.2014].

Lambie-Mumford, H. (2013) "Every town should have one": emergency food banking in the UK', Journal of Social Policy, 42, 1, 73-89.

Lambie-Mumford, H., Crossley, D., Jensen, E., Verbeke, M. and Dowler, E. (2014) Household Food Security: A Review of Food Aid, Report to Defra, https://www.gov.uk/government/publications/foodaid-research-report [accessed 21.02.2014].

Lang, T., Barling, D. and Caraher, M. (2009) Food Policy: Integrating Health, Environment and Society, Oxford: Oxford University Press.

Lucas, P., Jessiman, T. and Cameron, A. (2015) 'Healthy Start: the use of welfare food vouchers by lowincome parents in England', Social Policy and Society, forthcoming.

Lupton, D. (1996) Food, the Body and the Self, London: Sage.

Maslen, C., Raffle, A., Marriott, S. and Smith, N. (2013) Food Poverty: What Does the Evidence Tell Us?, Bristol: Bristol City Council.

Perry, J., Sefton, T., Williams, M. and Haddad, M. (2014) Emergency Use Only: Understanding and Reducing the Use of Food Banks in the UK, Oxford: Oxfam.

Poppendieck, J. (2014) 'Food assistance, hunger and the end of welfare in the USA', in G. Riches and T. Silvasti (eds.), First World Hunger Revisited: Food Charity or the Right to Food?, Basingstoke: Palgrave Macmillan, pp. 176-90.

Riches, G. (1997) 'Hunger and the welfare state: comparative perspectives', in G. Riches (ed.), First World Hunger: Food Security and Welfare Politics, Basingstoke: Macmillan Press, pp. 1-13.

Riches, G. and Tarasuk, V. (2014) 'Canada: thirty years of food charity and public policy neglect', in G. Riches and T. Silvasti (eds.), First World Hunger Revisited: Food Charity or the Right to Food?, Basingstoke: Palgrave Macmillan, pp. 42-56.

Riches, G. and Silvasti, T. (eds.) (2014) First World Hunger Revisited: Food Charity or the Right to Food?, Basingstoke: Palgrave Macmillan.

Royston, S. and Rodrigues, L. (2013) Nowhere to Turn? Changes to Emergency Support, London: The Children's Society.

Trussell Trust (2014) 'Latest foodbank figures top 900,000: life has got worse not better for poorest in 2013/14 and this is just the tip of the iceberg', press release, 16 April, http://www.trusselltrust. org/foodbank-figures-top-900000 [accessed 08.07.2014].

Which? (2013a) 'Waiting for the squeeze to end', Quarterly Consumer Report, July, http://www. staticwhich.co.uk/documents/pdf/quarterly-consumer-report-july-2013-327238.pdf.

Which? (2013b) 'Weathering the economic storm', Quarterly Consumer Report, October, http://www. staticwhich.co.uk/documents/pdf/quarterly-consumer-report-october-2013-338223.pdf [accessed 22.11.2013].

Wills, W. (2011) 'Introduction to food: representations and meanings', Sociological Research Online, 16, $2,16$.

Women's Budget Group (2012) Impact on Women of the Budget 2012, London: WBG, http://www.wbg.org.uk/RRB_Reports.htm [accessed 10.12.2014]. 